\title{
Excess enthalpies of binary and ternary mixtures containing dibutyl ether (DBE), cyclohexane and 1-butanol at 298.15 K
}

\begin{tabular}{|r|l|}
\hline Journal: & Journal of Chemical \& Engineering Data \\
\hline Manuscript ID: & je-2008-00751m.R1 \\
\hline Manuscript Type: & Article \\
\hline Duthor: & 13-Jan-2009 \\
\hline Complete List of Authors: & $\begin{array}{l}\text { Aguilar, Fernando; Universidad de Burgos, Ingeniería } \\
\text { Electromecánica } \\
\text { Alaoui, Fatima; Universidad de Burgos, Ingeniería Electromecánica } \\
\text { Alonso-Tristán, Cristina; Universidad de Burgos, Ingeniería } \\
\text { Electromecánica } \\
\text { SEGOVIA, JOSÉ; UNIVERSITY OF VALLADOLID, INGENIERÍA } \\
\text { ENERGÉTICA Y FLUIDOMECÁNICA } \\
\text { Villamanan, Miguel; Universidad de Valladolid, Depto. de Ingenieria } \\
\text { Energetica y Fluidomecánica } \\
\text { Montero, Eduardo; Universidad de Burgos, Ingeniería } \\
\text { Electromecánica }\end{array}$ \\
\hline
\end{tabular}

\section{ScholarONE \\ Manuscript Central}




\title{
Excess enthalpies of binary and ternary mixtures
}

\section{containing dibutyl ether (DBE), cyclohexane and 1-}

\section{butanol at $298.15 \mathrm{~K}^{1}$.}

\author{
Fernando Aguilar $^{(a)}$, Fatima E.M. Alaoui ${ }^{(a)}$, Cristina Alonso-Tristán ${ }^{(a)}$, José J. Segovia $^{(b)}$, Miguel A. \\ Villamañán $^{(b)}$ and Eduardo A. Montero ${ }^{(a), *}$ 09006 Burgos, Spain, Grupo de Termodinámica y Calibración TERMOCAL, E.T.S. de Ingenieros Industriales, Universidad de Valladolid, E-47071 Valladolid, Spain. \\ Departamento de Ingeniería Electromecánica, Escuela Politécnica Superior, Universidad de Burgos, E-
}

RECEIVED DATE (to be automatically inserted after your manuscript is accepted if required according to the journal that you are submitting your paper to)

*Corresponding author. E-mail: emontero@ubu.es. Tel. +34 947258 916. Fax: +34 947259088

(a) Universidad de Burgos

${ }^{\text {(b) }}$ Universidad de Valladolid

${ }^{1}$ This paper is part of the Doctoral Thesis of F. Aguilar.

Experimental excess enthalpies of the ternary system dibutyl ether (DBE) + cyclohexane +1 -butanol and the corresponding binary systems at $298.15 \mathrm{~K}$ are reported. A quasi-isothermal flow calorimeter has been built and tested to make the measurements. All the binary and the ternary systems show endothermic character. The experimental data have been fitted using a polynomial equation for the 
binary and ternary systems. The values of the standard deviation indicate good agreement between the experimental results and these calculated from the equation.

\section{Introduction}

The use of oxygenated compounds as gasoline-blending agents has been proposed to reduce emissions of new reformulated gasoline. Ether + alkane + alcohol mixtures are of interest as model mixtures for gasoline in which the alcohol and the ether act as non-polluting, high octane number blending agents. From this point of view the study of the ternary mixture dibutyl ether + cyclohexane +1 -butanol is very interesting. Cyclohexane is an usual compound of gasoline; dibutyl ether (DBE) is used as blending agent in reformulated gasoline and 1-butanol is a basic component in the synthesis of the ether, and therefore is always contained as an impurity. Experimental excess enthalpies of the ternary system DBE + cyclohexane +1 -butanol and the corresponding binary systems at $298.15 \mathrm{~K}$ are reported in this work. Excess enthalpies have been measured with a new quasi-isothermal flow calorimeter recently built at the University of Burgos. The experimental data have been fitted using a Redlich-Kister ${ }^{1}$ equation and NRTL $^{2}$ and UNIQUAC ${ }^{3}$ models. The values of the standard deviation indicate the agreement between the experimental results and these calculated from the equations.

\section{Experimental Section}

Materials. All the chemicals used here were purchased from Fluka Chemie AG and were of the highest purity available, chromatography quality reagents (of the series puriss p.a.) with a stated purity $>99.5 \%$. All reagents were checked by gas chromatography, and the values of purity obtained were $>99.6 \%$ for DBE, $>99.9 \%$ for cyclohexane and $>99.8 \%$ for 1-butanol. The water content for 1-butanol was checked to be less than $0.009 \%$.

Apparatus and Procedure. Excess enthalpies have been measured with a new quasi-isothermal flow calorimeter recently built at the University of Burgos, based on the previous experience of the research group. ${ }^{4,5}$ Figure 1 shows schematically the quasi-isothermal calorimeter. Two precision positive displacement pumps (Agilent, model 1100) deliver the liquids through stainless-steel tubing at 
programmable constant flow rates into the mixing coil sitting in the flow cell, which is included in the measure unit, following the scheme shown in Figure 2. The flow cell has been built in the TERMOCAL laboratory at the University of Valladolid. In case of binary systems, the two liquids are the pure components and, in case of ternary systems, one of them is a pure component and the other the corresponding binary mixture. The flow cell is immersed in a water bath, (Hart Scientific, model 6020E) thermostatted at the temperature the mixing process is taking place. The stability of the temperature is better than $\pm 0.01 \mathrm{~K}$. The bath temperature is measured by its calibrated standard PRT-100, resolving 10 $\mathrm{mK}$ in the reading of temperature and estimating an overall uncertainty of $\pm 30 \mathrm{mK}$.

Isothermal calorimetry is based on measuring the energy required to maintain the mixing vessel at a constant temperature. To achieve this condition, a Peltier cooler removes at a constant rate energy from the flow cell and a control-heater compensates this energy and additionally the energy liberated (exothermic) or absorbed (endothermic) by the mixing process and maintains the temperature of the flow cell constant. The variation of temperature is detected by a control sensor, a NTC thermistor. The resistance is measured by a 4-wire resistance bridge with a micro-ohm meter from Hewlett-Packard, model HP-34420A. The Peltier cooler, the control-heater and the calibration heater are connected, each one, to its respectively DC power supply. The control of these devices is made by a computer through a GPIB connection and a specific software that has been developed. The change of heating power of the control-heater before, during and after measurements is a direct measure for the excess enthalpy $H^{E}$. The calibration of the measurement system is made by simulating an exothermic mixing process by a calibration resistor.

Knowing the volumetric flow rates delivered, the molar masses and the densities of the pure compounds, the mole fractions of the mixtures obtained in the mixing coil can be calculated. The maximum absolute uncertainty of mole fraction at equimolar composition is \pm 0.0008 . Densities of pure liquids are determined interpolating density data obtained from Riddick et al. ${ }^{6}$ at the measured temperature of delivery. Table 1 shows agreement between our estimated density data and literature data. The temperature of pure liquids is measured by a calibrated standard PRT-100 inserted in the pump 
body, using as indicator an a/c resistance bridge (ASL model F250) resolving $1 \mathrm{mK}$ in the reading of temperature and estimating an overall uncertainty of $\pm 10 \mathrm{mK}$. Mixtures of different compositions are studied by changing the ratio of flow rates and in this way the dependence of $H^{E}$ on mole fraction can be determined. The estimated relative uncertainty of the determined $H^{E} / \mathrm{J} \cdot \mathrm{mol}^{-1}$ is $\pm 0.01 \cdot H^{E}$.

To check the above apparatus we have used two systems traditionally considered as test systems for calorimetric techniques: cyclohexane + hexane and benzene + cyclohexane at $298.15 \mathrm{~K}$. The first system, cyclohexane (1) + hexane (2), was measured by Marsh and Stokes ${ }^{12}$ with an isothermal displacement microcalorimeter. This work presents the most complete amount of data and is taken as reference system. However, we have considered also the comparison with data from Murakami et al. ${ }^{13}$, which used a continuous dilution calorimeter, and from Gmehling et al. ${ }^{14}$, whose data were taken with an isothermal flow calorimeter of the same characteristics as ours. Table 2 presents the results found in the references for this system and the results obtained in this work, as well as the maximum deviation of the excess enthalpy respect the calculated value, $\max \left|\Delta H^{E}\right|$, and the standard deviation, rms $\Delta H^{E}$. The Redlich-Kister equation is used for the adjustment of each data set, with the number of parameters employed by each author:

$$
H^{E}=x \cdot(1-x) \cdot \sum_{i=1}^{n} A_{i} \cdot(2 x-1)^{i-1}
$$

The comparison of the calculated values of the Redlich-Kister coefficients and scattering parameters in this work with those from the literature, shows that our values are similar with regard to the same type of isothermal flow calorimeter and more scattered in relation with isothermal displacement microcalorimeter and continuous dilution calorimeter.

A comparison between experimental data of this work and those from the literature is presented in Figure 3. For each data set, the calculated enthalpy $H_{c a l c}^{E}$ has been determined using the Redlich-Kister coefficients of the correlation determined by Marsh and Stokes ${ }^{12}$. The scattering of experimental data obtained in this work is within the $\pm 1 \%$ of the calculated enthalpy corresponding to each mole fraction in the central range of composition. 
The second test system is the binary mixture benzene (1) + cyclohexane (2) at $298.15 \mathrm{~K}$. In a similar way as for the former system, comparison between the data of Ewing et al. ${ }^{15}$, Lundberg ${ }^{16}$, Savini et al. ${ }^{17}$ and this work is reported in Table 2 and Figure 3, being the coefficients of Ewing et al. ${ }^{15}$ used to obtain the calculated enthalpy $H^{E}$ calc for each data set. In this case, also the agreement between this work and literature data is within the $\pm 1 \%$ of the calculated enthalpy.

\section{Results and Discussion}

The experimental excess molar enthalpies obtained in this work for the binary mixtures DBE (1) + cyclohexane (2), DBE (1) + 1-butanol (3) and cyclohexane (2) + 1-butanol (3) at 298.15 K are listed in Table 3.

For binary systems, there are several models and empirical equations proposed to fit the $H^{E}$ measurements. One of them, the Redlich-Kister equation, is given by eq. 1 , in which the $A_{i}$ coefficients are determined by the unweighted least-squares method. Another equation very employed is the modified Margules eq. 2, proposed by Abbot and van Ness ${ }^{18}$

$$
H^{E}=x_{1} x_{2} R T\left[a_{21} x_{1}+a_{12} x_{2}-\frac{x_{1} x_{2} b_{12} b_{21}}{b_{21} x_{1}+b_{12} x_{2}+x_{1} x_{2}\left(c_{21} x_{1}+c_{12} x_{2}\right)}\right]
$$

Binary systems have also been correlated using NRTL model, which expression for the molar excess enthalpy is indicated by the eq. 3 :

$$
H^{E}=-R T \sum_{i=1}^{n} x_{i} \eta_{i}
$$

where $x_{i}$ is the mole fraction of the component $i$ and $\eta_{t}$ is given by

$$
\begin{gathered}
\eta_{i}=\frac{\sum_{k=1}^{p} x_{k} \tau_{k i} G_{k i}\left[\alpha\left(\tau_{k i}-\left(\sum_{n=1}^{p} x_{n} \tau_{n i} G_{n i} / \sum_{l=1}^{n} x_{l} G_{l i}\right)\right)-1\right]}{\sum_{l=1}^{p} x_{l} G_{l i}} \\
G_{j i}=\exp \left(-\alpha \tau_{i j}\right)
\end{gathered}
$$


The NRTL theory assumes that the excess molar enthalpy of a multicomponent mixture depends only on the binary parameters. In this work, the non-randomness parameter $\alpha$ was assigned 0.3 for the NRTL model of two parameters, and as an adjustable parameter for the NRTL model of three parameters.

For the UNIQUAC model, the molar excess enthalpy is given by

$$
H^{E}=\sum_{i=1}^{n} q_{i} x_{i} \frac{\sum_{j=1}^{n} \vartheta_{j} \Delta u_{j i} \tau_{j i}}{\sum_{j=1}^{n} \vartheta_{j} \tau_{i j}}
$$

where $\vartheta_{i}=\frac{q_{i} x_{i}}{\sum_{j} q_{j} x_{j}}$ and $q_{i}$ the molecular surface area, obtained as the sum of the contributions of the functional groups presents in the compound.

Results of data correlation for the binary systems are summarized in Table 4. A plot of the experimental and correlated data is shown in Figure 4.

The ternary mixtures DBE (1) + cyclohexane (2) + 1-butanol (3) at $298.15 \mathrm{~K}$ were formed by adding the cyclohexane (2) to binary mixtures of fixed composition of DBE (1) + 1-butanol (3). Four different starting binaries were used, with values of the ratio $x_{1} / x_{3}$ of $0.2498,0.6669,1.4988$ and 4.0531 respectively. The experimental excess molar enthalpies listed in Table 5 are determined by eq. 5 , using the smooth representation of $H^{E}{ }_{13}$ by Redlich-Kister:

$$
H_{123}^{E}=H_{2+13}^{E}+\left(1-x_{2}\right) H_{13}^{E}
$$

Experimental results for the excess molar enthalpy $H^{E}{ }_{123}$ are shown in Figure 5.

The following equation was used to fit the $H^{E}$ measurements

$$
H_{123}^{E}=H_{12}^{E}+H_{13}^{E}+H_{23}^{E}+x_{1} x_{2} x_{3} \Delta H_{123}^{E}
$$

with

$$
\Delta H_{123}^{E}=B_{0}+B_{1} x_{1}+B_{2} x_{2}+B_{3} x_{1}^{2}+B_{4} x_{2}^{2}+B_{5} x_{1} x_{2}+B_{6} x_{1}^{3}+B_{7} x_{2}^{3}
$$

where the parameters $B_{i}$ were determined by the unweighted least-squares method. Another alternative for the calculation of $\Delta H^{E}{ }_{123}$ is eq. 8 


$$
\Delta H_{123}^{E}=B_{1} x_{1}+B_{2} x_{2}+B_{3} x_{3}
$$

Table 6 presents the summary of correlation results obtained for the ternary system with eq. $6,7,8$, and NRTL and UNIQUAC models. Table 6 also shows the prediction results obtained for the ternary system using the parameters of the binary systems.

The excess molar enthalpy of the system DBE (1) + cyclohexane (2) at 298.15 K shows endothermic behaviour $\left(H^{E}>0\right)$ in the whole range of composition. The best fit of experimental data is obtained with the Redlich-Kister equation with a root mean square deviation, $\mathrm{rms} \Delta H^{E}$, of $0.5 \mathrm{~J} \cdot \mathrm{mol}^{-1}$ and a maximum value of the absolute deviation, $\max \left|\Delta H^{E}\right|$, of $1.2 \mathrm{~J} \cdot \mathrm{mol}^{-1}$. Deviations obtained with NRTL and UNIQUAC models are higher. The maximum value of the molar excess enthalpy is $267 \mathrm{~J} \cdot \mathrm{mol}^{-1}$, obtained at a mole fraction of DBE about 0.40 . Comparison with data for the same binary system and temperature reported by Marongiu et al. ${ }^{19}$ shows that our $H^{E}$ data are considerably higher, the difference being $15 \%$ in the central range of composition, even when the calorimeter was re-calibrated and the binary system measured three times.

The binary system DBE (1) + 1-butanol (3) measured at 298.15 K is also endothermic. The maximum value of $H^{E}$ is $892 \mathrm{~J} \cdot \mathrm{mol}^{-1}$, at a mole fraction of DBE about 0.60 . Modified Margules equation gives the best fit with a root mean square deviation, $\mathrm{rms} \Delta H^{E}$, of $2.4 \mathrm{~J} \cdot \mathrm{mol}^{-1}$ at $298.15 \mathrm{~K}$. The maximum values of the absolute deviation, $\max \left|\Delta H^{E}\right|$, is $4.0 \mathrm{~J} \cdot \mathrm{mol}^{-1}$. The remaining models give worse fits. Our $H^{E}$ data agree to within $1,5 \%$ in the central range of composition with the measurements for the same system and temperature obtained from Kammerer and Lichtenthaler. ${ }^{20}$

The third binary system which has been studied is the system cyclohexane $(2)+1$-butanol (3) at 298.15 K, showing also an endothermic behaviour. The maximum value of the molar excess enthalpy of the mixture is $635 \mathrm{~J} \cdot \mathrm{mol}^{-1}$. The mole fraction of cyclohexane at this maximum is approximately 0.65. The experimental data have been fitted by Redlich-Kister, modified Margules, NRTL and UNIQUAC models, being the Modified Margules equation the best fit with a root mean square deviation, $\mathrm{rms} \Delta H^{E}$, of $2.6 \mathrm{~J} \cdot \mathrm{mol}^{-1}$. The maximum value of the absolute deviation, $\max \left|\Delta H^{E}\right|$, is $6.0 \mathrm{~J} \cdot \mathrm{mol}^{-1}$. Comparison with 
data for the same binary system and temperature reported by Löwen and Schulz ${ }^{21}$ shows that our $H^{E}$ data agree to within $1.7 \%$ in the central range of composition.

Concerning the measured ternary system, the best fit of experimental data is obtained with eq. 6 and 7. The root mean square deviation, $\mathrm{rms} \Delta H^{E}$, is of $5.0 \mathrm{~J} \cdot \mathrm{mol}^{-1}$, and the maximum value of the absolute deviation, $\max \left|\Delta H^{E}\right|$, is $13.4 \mathrm{~J} \cdot \mathrm{mol}^{-1}$ which means about $5 \%$ over the experimental molar excess enthalpy at this point. The results obtained with the other models are rather worse. This system shows an endothermic behaviour in the whole range of composition. The maximum value of $H^{E}$ is $890 \mathrm{~J} \cdot \mathrm{mol}^{-1}$. No data of the same system were found in the literature for comparison. Both NRTL and UNIQUAC models present high root mean square deviation values in the prediction of data.

\section{Conclusions}

Isothermal excess enthalpies at $298.15 \mathrm{~K}$ for the ternary system dibutyl ether (DBE) + cyclohexane + 1-butanol and its constituent binary systems were determined by using an isothermal flow calorimeter. All the binary systems show positive values and strongly asymmetric $H^{E}$ behavior in the measured temperature. The measured excess enthalpies data were correlated well with various common $H^{E}$ models. 


\section{FIGURE CAPTIONS}

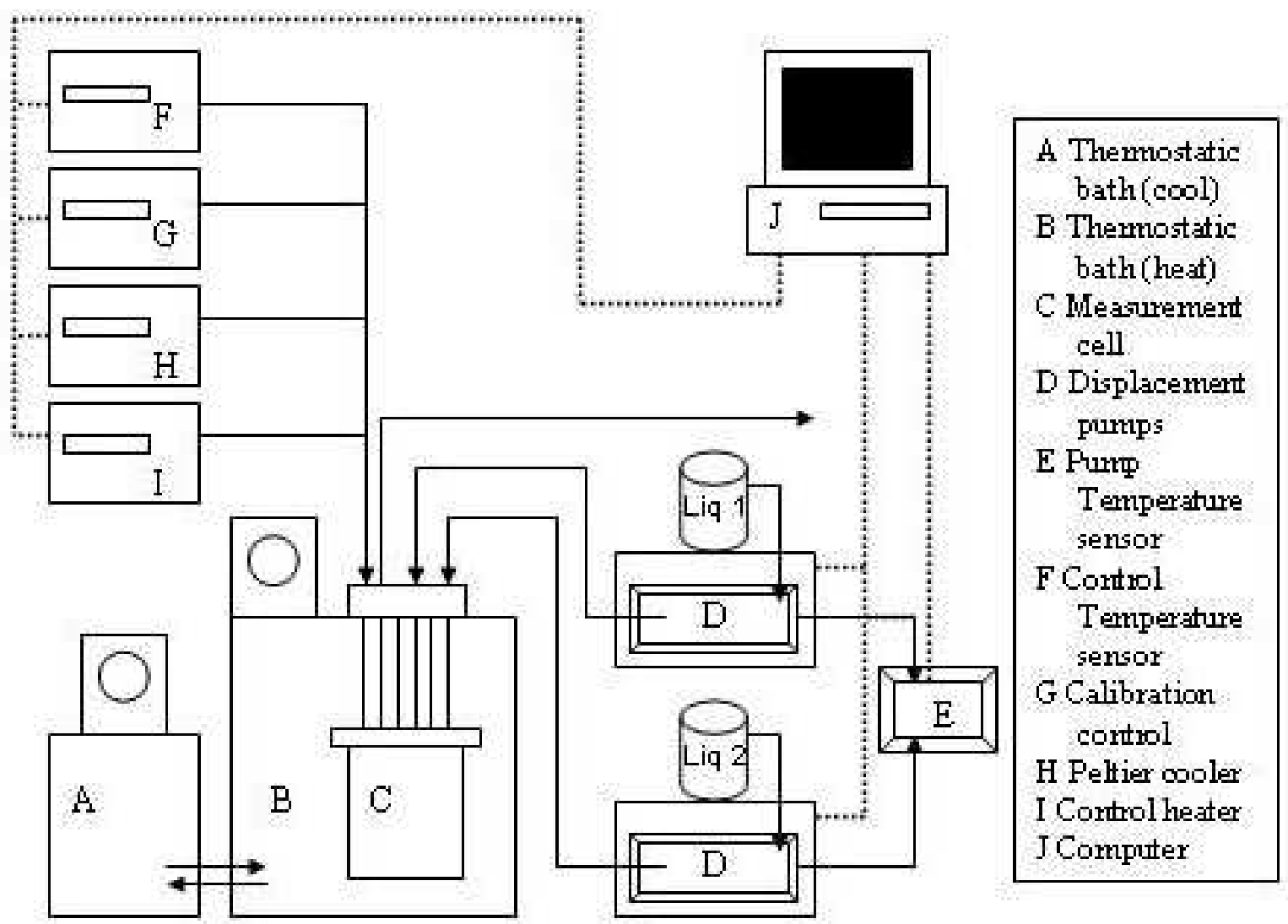

Figure 1. Quasi-isothermal flow calorimeter. Schematic diagram. 


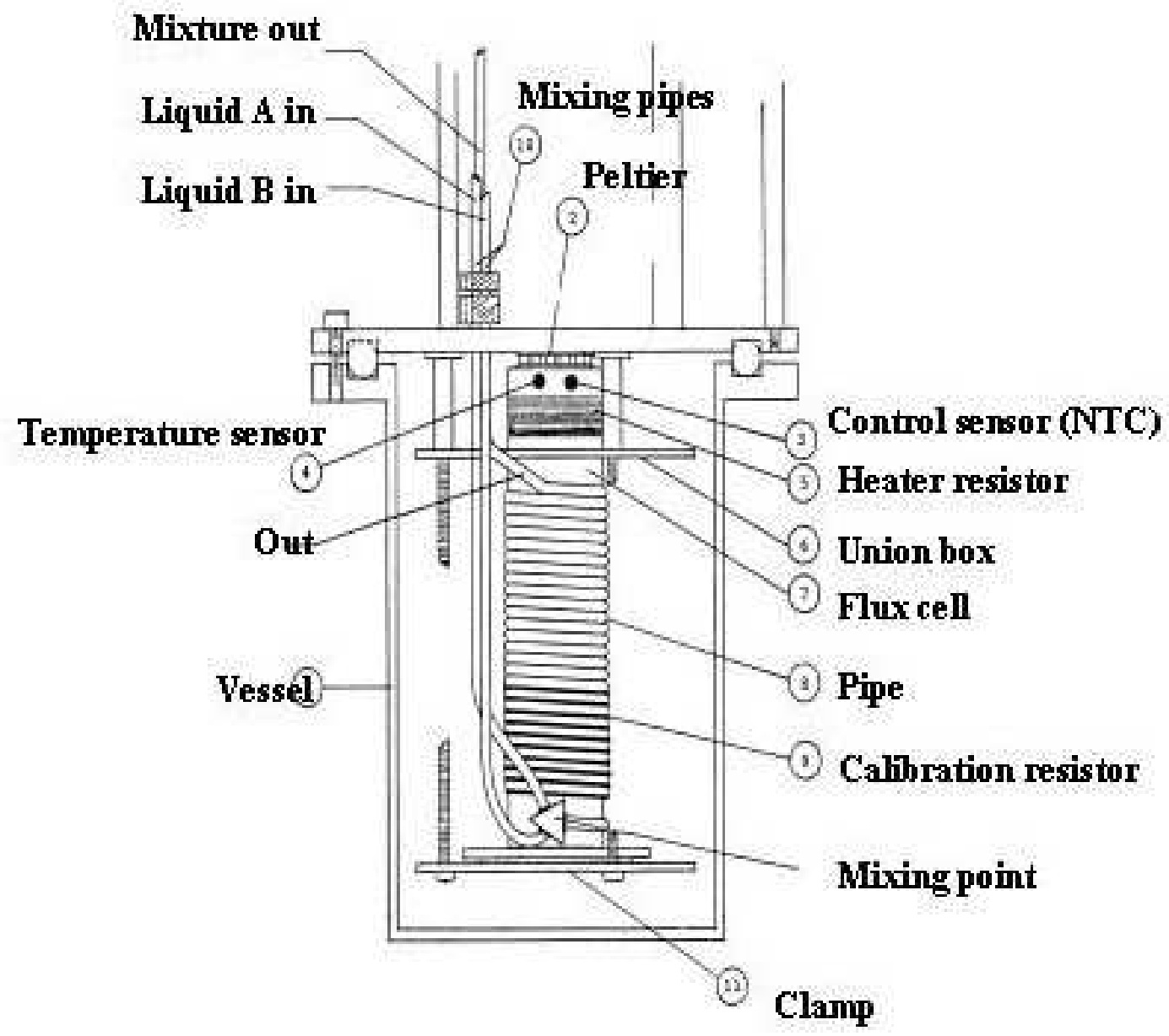

Figure 2. Mixing flow cell. Schematic diagram. 


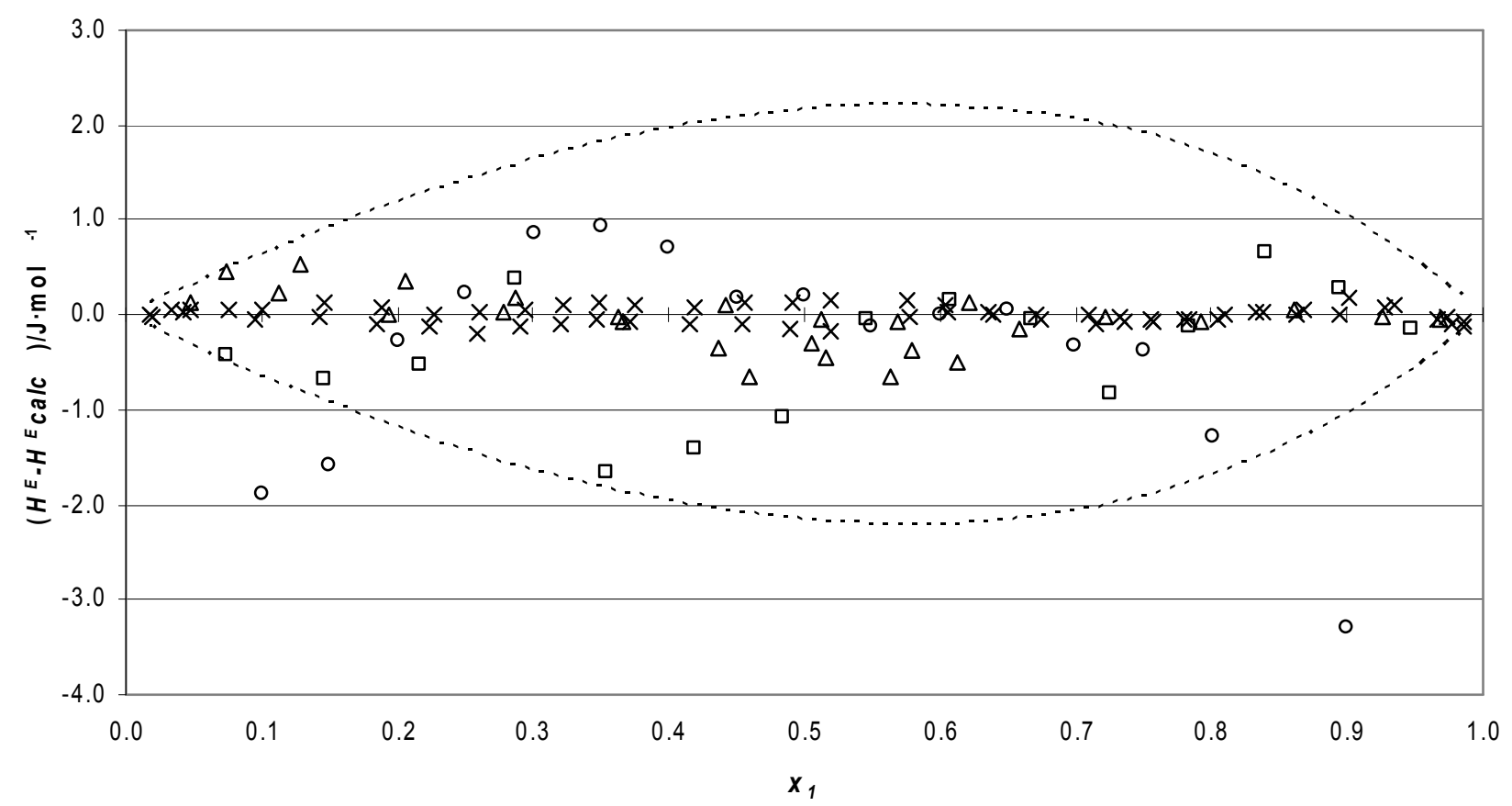

(a)

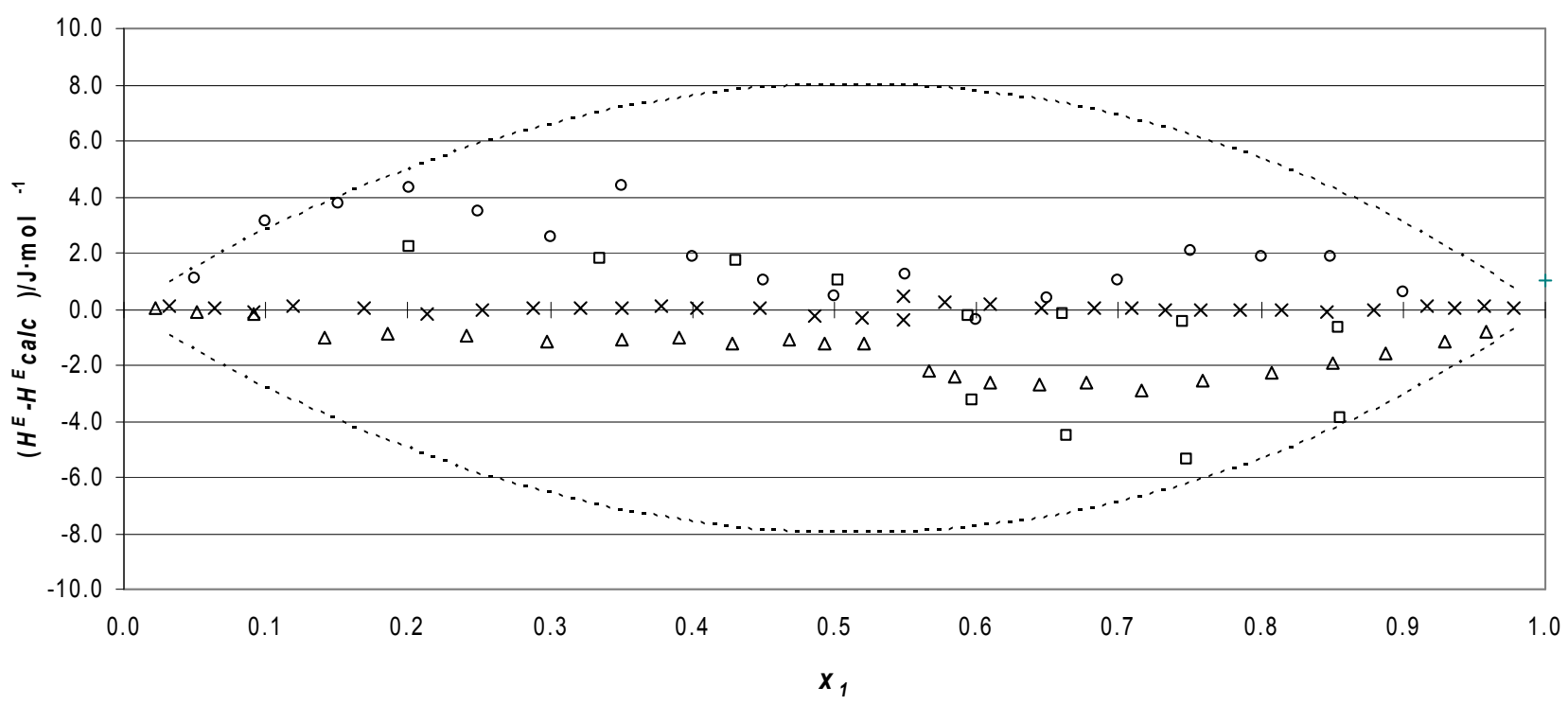

(b)

Figure 3. Comparison of residuals between the measured excess enthalpy, $H^{E}$, and the calculated excess enthalpy, $H_{c a l c}^{E}$, at the temperature of $298.15 \mathrm{~K}$, for the following systems: (a) Cyclohexane (1) + Hexane (2), O, This work; x, Marsh and Stokes ${ }^{12} ; \Delta$, Murakami and Benson ${ }^{13} ; \square$, Gmehling and 
Meents ${ }^{14}$. (b) Benzene (1) + Cyclohexane (2), O, This work; x, Ewing et al..$^{15}$; $\square$ Lundberg ${ }^{16} ; \Delta$, Savini et al. ${ }^{17}$.

In Figure 3(a), the calculated enthalpy $H^{E}$ calc has been determined using the Redlich-Kister coefficients of the correlation determined by Marsh and Stokes ${ }^{7}$ for each data set, while those from Ewing et al. ${ }^{15}$ have been used in Figure 3(b). The dotted line shows the $\pm 1 \%$ deviation from the calculated enthalpy corresponding to each mole fraction. 


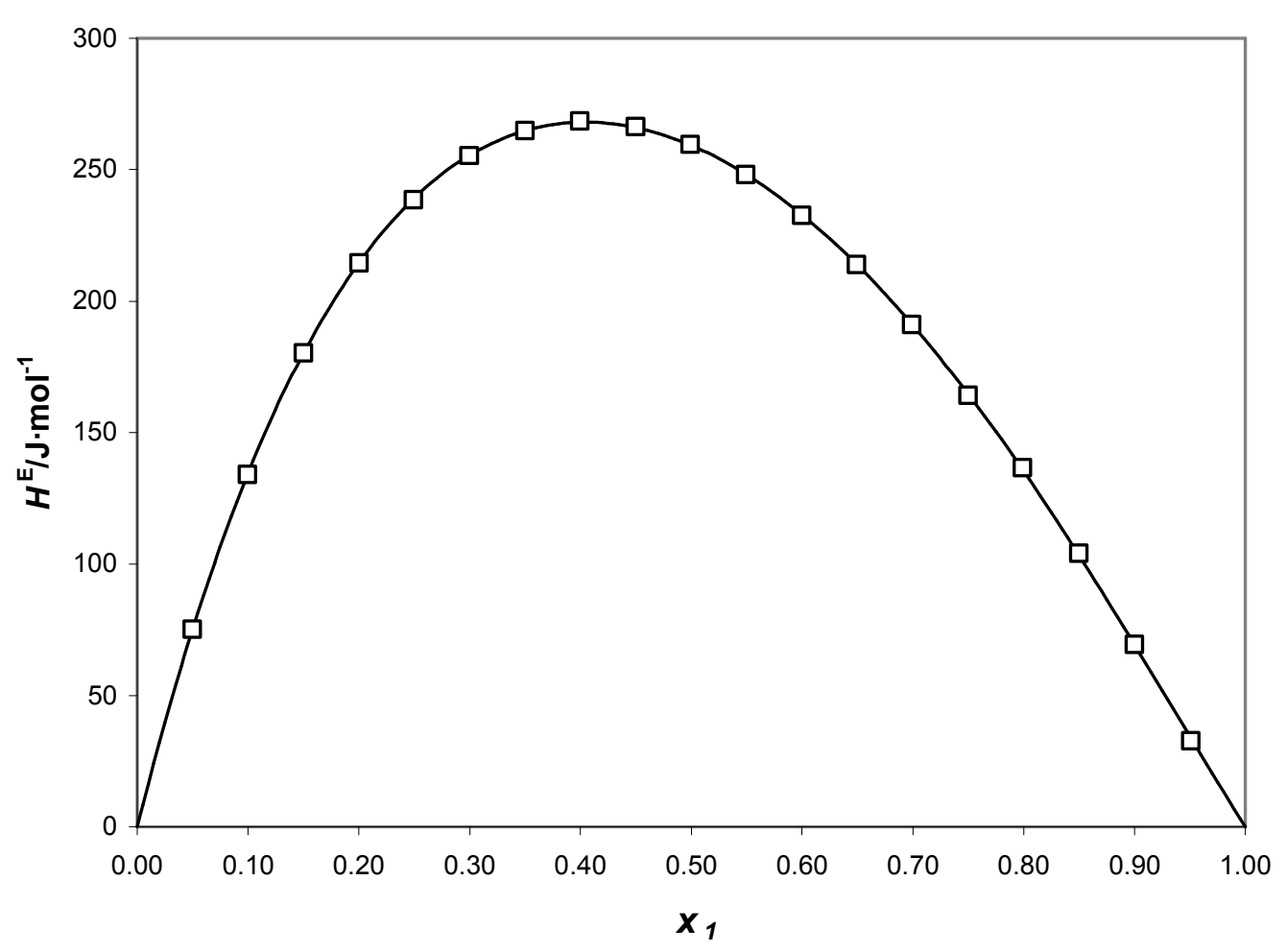

(a)

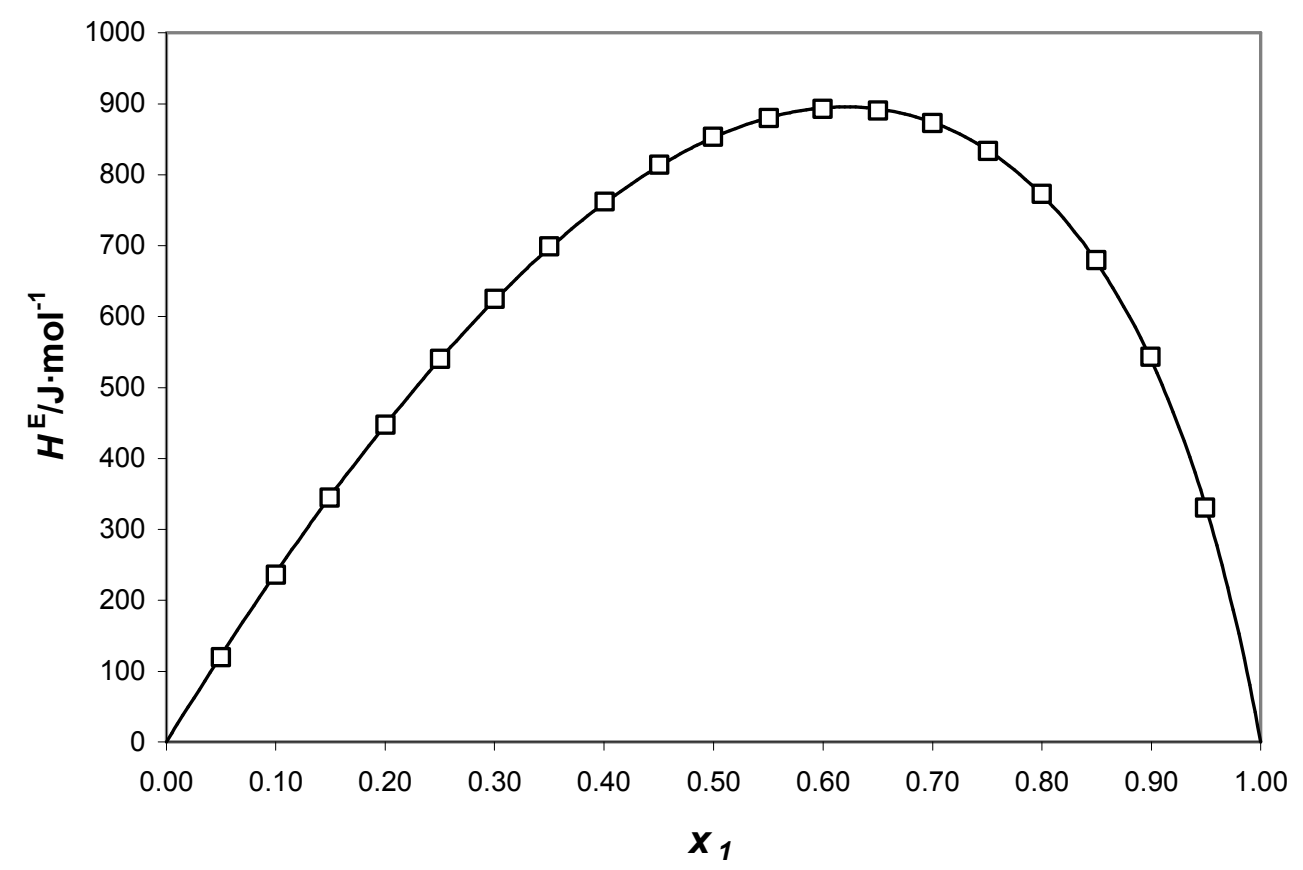

(b) 


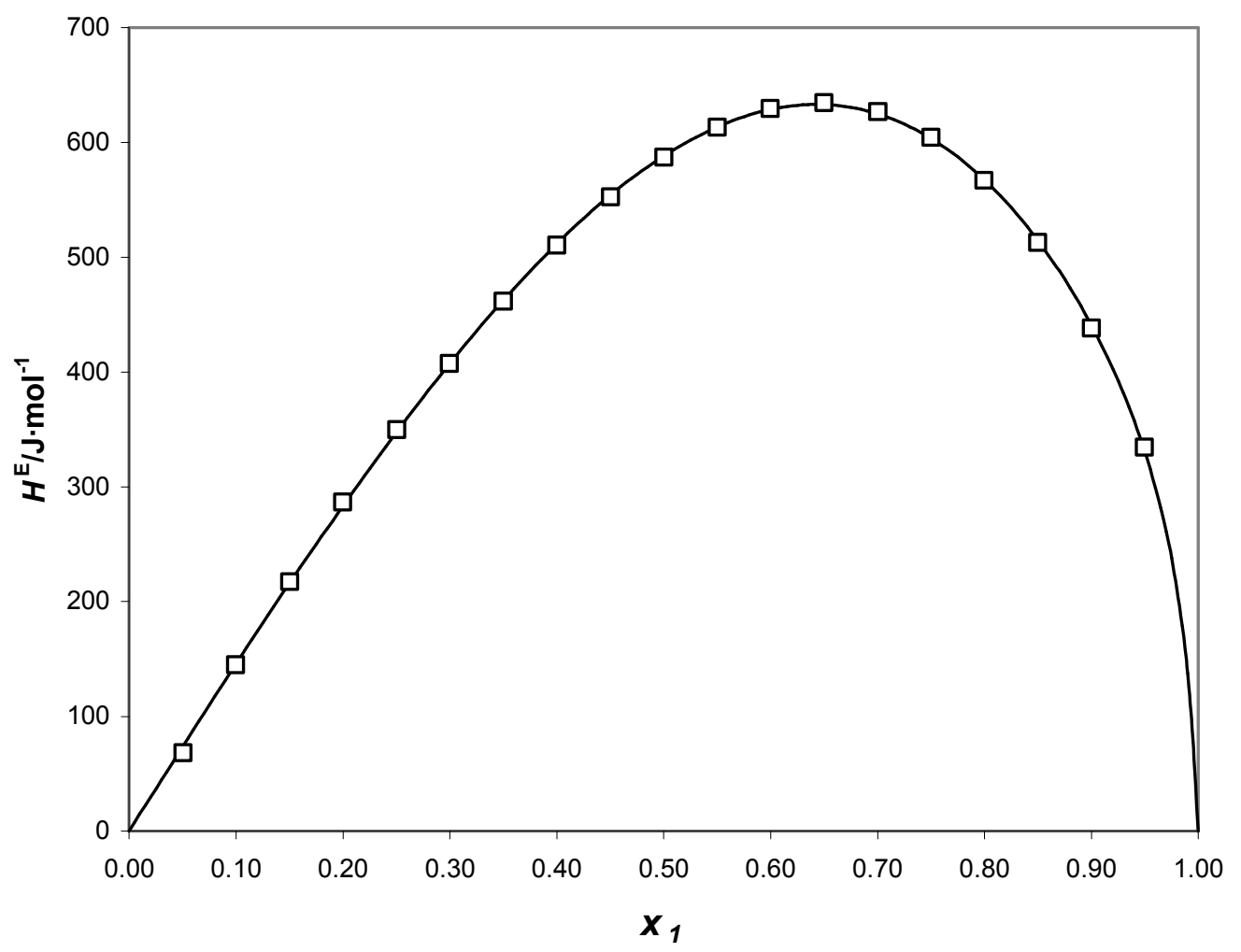

(c)

Figure 4. Excess molar enthalpy $H^{E}$ at $298.15 \mathrm{~K}$ for (a) DBE (1) + cyclohexane (2); (b) DBE (1) + 1butanol (3); (c) cyclohexane (2) + 1-butanol (3). Experimental results: $(\square)$; ( _ $)$ calculated with eq. 1 (Figure a) and eq. 2 (Figures $\mathrm{b}$ and c) using parameters of Table 4. 


1
2
3
4
5
6
7
8
9
10
11
12
13
14
15
16
17
18
19
20
21
22
23
24
25
26
27
28
29
30
31
32
33
34
35
36
37
38
39
40
41
42
43
44
45
46
47
50
58
59
50
52
53
50

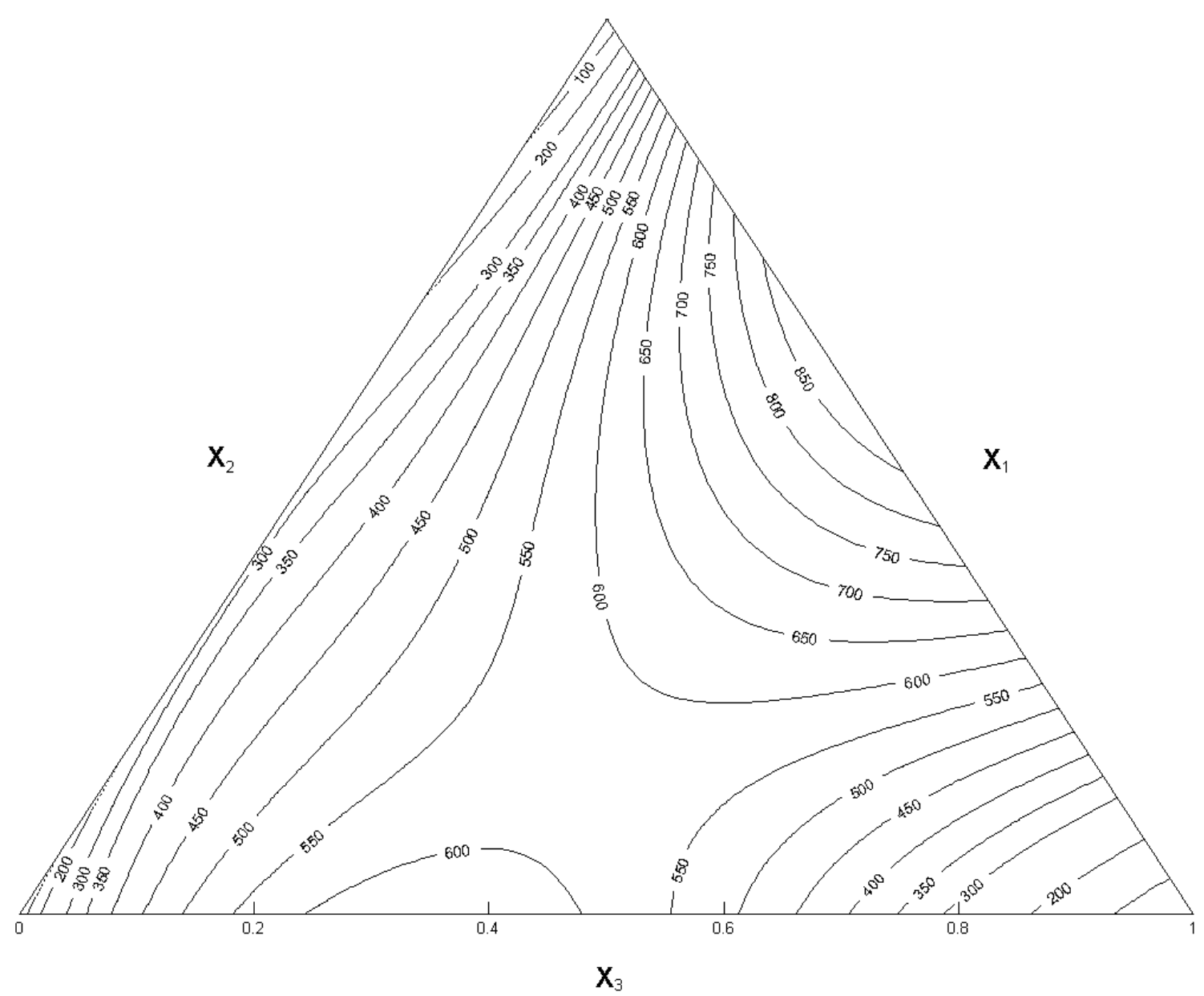

Figure 5. Contours for constant values of $H_{123}^{E}$ for DBE(1) + cyclohexane (2) + 1-butanol (3) at 298.15

K. 


\section{TABLES.}

Table 1. Comparison of density data of pure compounds, cyclohexane, hexane, benzene, DBE and 1butanol, at $298.15 \mathrm{~K}$.

\begin{tabular}{|c|c|c|c|c|c|c|c|c|c|c|}
\hline & cycloh & xane & hex & ane & ben & ene & $\overline{\mathrm{DH}}$ & & 1-bu & $\overline{a n o l}$ \\
\hline & $\begin{array}{l}\text { this } \\
\text { work }\end{array}$ & lit. & $\begin{array}{c}\text { this } \\
\text { work }\end{array}$ & lit. & $\begin{array}{c}\text { this } \\
\text { work }\end{array}$ & lit. & $\begin{array}{c}\text { this } \\
\text { work }\end{array}$ & lit. & $\begin{array}{c}\text { this } \\
\text { work }\end{array}$ & lit. \\
\hline$U_{1}$ & $0.77389^{\mathrm{a}}$ & $.7738^{b}$ & $0.65484^{\mathrm{a}}$ & $0.6551^{c}$ & $0.87360^{\mathrm{a}}$ & $0.8736^{\mathrm{d}}$ & $0.76410^{\mathrm{a}}$ & $0.76411^{\mathrm{e}}$ & $0.80575^{\mathrm{a}}$ & $0.80561^{\mathrm{f}}$ \\
\hline
\end{tabular}

${ }^{\mathrm{a}}$ Riddick et al. ${ }^{6} .{ }^{\mathrm{b}}$ Rodríguez et al. ${ }^{7}$ ' Iglesias et al. ${ }^{8} .{ }^{\mathrm{d}}$ Iglesias et al. ${ }^{9} .{ }^{\mathrm{e}} \mathrm{Jiménez}$ et al. ${ }^{10}$. ${ }^{\mathrm{f}}$ Rezanova et al. ${ }^{11}$. 
Table 2. Comparison of $H^{E}$ data for the binary systems cyclohexane + hexane and benzene + cyclohexane, at $298.15 \mathrm{~K}$. Parameters $A_{i}$ of Redlich-Kister equation, standard deviation rms $\Delta H^{E}$ and maximum excess enthalpy deviation max. $\left|\Delta H^{E}\right|$.

\begin{tabular}{|c|c|c|c|c|c|c|}
\hline $\begin{array}{l}\text { Calorimeter } \\
\text { technique }\end{array}$ & $A_{1}$ & $A_{2}$ & $A_{3}$ & $A_{4}$ & $\begin{array}{l}\mathrm{rms} \Delta H^{E} \\
/ \mathrm{J} \cdot \mathrm{mol}^{-1}\end{array}$ & \begin{tabular}{c|c}
$\max$. & $\Delta H^{E}$ \\
$/ \mathrm{J} \cdot \mathrm{mol}^{-1}$
\end{tabular} \\
\hline
\end{tabular}

Isothermal displacement calorimeter. ${ }^{\mathrm{a}}$

$\begin{array}{llll}864.7 & 249.5 & 99.1 & 33.2\end{array}$

0.1

0.2

Continuous dilution $863.5 \quad 248.8$ 104.5 31.1

0.2 0.4 calorimeter. $^{\mathrm{b}}$

Isothermal

flow $\begin{array}{lll}861.6 & 264.4 \quad 103.8\end{array}$

0.8 1.6 calorimeter. $^{\mathrm{c}}$

Isothermal

flow $\begin{array}{lll}867.2 & 245.3 \quad 63.8\end{array}$ 23.7

0.8 1.4 calorimeter. $^{\mathrm{d}}$

Benzene (1) + Cyclohexane (2)

Isothermal displacement calorimeter. $^{\mathrm{e}}$ $\begin{array}{llll}3197.1 & 175.4 & 121.5 & 28.5\end{array}$

0.2

0.5

Continuous

dilution $3196.7 \quad 153.9 \quad 123.0$

2.0

calorimeter. $^{\mathrm{f}}$

Continuous

dilution 3190.4

163.5

112.5

36.7

0.3

0.6

calorimeter. $^{\mathrm{g}}$

Isothermal

flow

$3201.3 \quad 171.8 \quad 151.5$

0.9

2.3 calorimeter. $^{\mathrm{d}}$

${ }^{\mathrm{a}}$ Marsh and Stokes ${ }^{12}$. ${ }^{\mathrm{b}}$ Murakami and Benson ${ }^{13}$. ${ }^{\mathrm{c}}$ Gmehling and Meents ${ }^{14}$. ${ }^{\mathrm{e}}$ Ewing et al. ${ }^{15}$. Lundberg $^{16}$. ${ }^{\mathrm{g}}$ Savini et $\mathrm{al}{ }^{17}$. ${ }^{\mathrm{d}}$ This work 
Table 3. Experimental excess molar enthalpies of binary systems DBE (1)+ cyclohexane (2), DBE (1) + 1-butanol (3) and cyclohexane (2) + 1-butanol (3) at 298.15 K.

\begin{tabular}{|c|c|c|c|c|c|c|c|}
\hline$x$ & $H^{E} / \mathrm{J} \cdot \mathrm{mol}^{-1}$ & $x$ & $H^{E} / \mathrm{J} \cdot \mathrm{mol}^{-1}$ & $x$ & $H^{E} / \mathrm{J} \cdot \mathrm{mol}^{-1}$ & $x$ & $H^{E} / \mathrm{J} \cdot \mathrm{mol}^{-1}$ \\
\hline \multicolumn{8}{|c|}{$x \mathrm{DBE}+(1-x)$ cyclohexane } \\
\hline 0.0499 & 75.2 & 0.2999 & 255.4 & 0.5495 & 248.1 & 0.7990 & 136.7 \\
\hline 0.0997 & 134.1 & 0.3500 & 264.9 & 0.6000 & 232.6 & 0.8500 & 104.1 \\
\hline 0.1502 & 180.4 & 0.3996 & 268.6 & 0.6491 & 213.9 & 0.9001 & 69.3 \\
\hline 0.2002 & 214.5 & 0.4497 & 266.4 & 0.6992 & 191.1 & 0.9507 & 32.8 \\
\hline 0.2497 & 238.5 & 0.4990 & 259.6 & 0.7501 & 164.1 & & \\
\hline \multicolumn{8}{|c|}{$x \mathrm{DBE}+(1-x) 1$-butanol } \\
\hline 0.0501 & 119.4 & 0.3004 & 624.6 & 0.5506 & 879.8 & 0.8000 & 772.8 \\
\hline 0.1002 & 236.0 & 0.3498 & 698.4 & 0.5998 & 892.4 & 0.8501 & 679.1 \\
\hline 0.1497 & 344.5 & 0.4006 & 762.1 & 0.6505 & 890.6 & 0.8994 & 543.1 \\
\hline 0.2003 & 447.6 & 0.4507 & 814.0 & 0.7000 & 872.6 & 0.9493 & 330.1 \\
\hline 0.2503 & 540.2 & 0.4997 & 853.2 & 0.7509 & 833.2 & & \\
\hline \multicolumn{8}{|c|}{$x$ cyclohexane $+(1-x) 1$-butanol } \\
\hline 0.0503 & 68.3 & 0.2997 & 407.6 & 0.5501 & 613.4 & 0.7996 & 567.1 \\
\hline 0.0998 & 144.8 & 0.3500 & 461.6 & 0.5997 & 629.5 & 0.8500 & 513.0 \\
\hline 0.1502 & 217.4 & 0.4002 & 510.5 & 0.6501 & 634.6 & 0.9000 & 438.5 \\
\hline 0.1998 & 286.8 & 0.4503 & 552.5 & 0.7002 & 626.7 & 0.9496 & 334.4 \\
\hline 0.2502 & 349.6 & 0.5003 & 587.3 & 0.7501 & 604.7 & & \\
\hline
\end{tabular}


Table 4. Summary of parameters for the representation of $H^{E}$ by Redlich-Kister, Modified Margules equation, NRTL (2 and 3 parameters) and UNIQUAC models, for binary systems DBE (1) + cyclohexane (2), DBE (1) + 1-butanol (3) and cyclohexane (2) + 1-butanol (3) at 298.15 K.

\begin{tabular}{|c|c|c|c|c|c|}
\hline Binary Systems $^{\mathrm{a}}$ & & & Correlatic & & \\
\hline DBE (1)+ cyclohexane (2) & $\begin{array}{l}\text { Redlich- } \\
\text { Kister }\end{array}$ & $\begin{array}{l}\text { Modified } \\
\text { Margules }\end{array}$ & NRTL & NRTL(3p) & UNIQUAC \\
\hline$\sqrt{3+3}$ & 1037.1 & 0.979 & -0.2065 & 0.1153 & -210.2 \\
\hline$A_{1}$ & -362.2 & 0.277 & 0.8622 & 0.5691 & 467.4 \\
\hline$A_{2}$ & 166.2 & 0.328 & & & \\
\hline$A_{3}$ & -139.2 & 117.8 & & & \\
\hline$A_{4}$ & -29.0 & 2.6 & & & \\
\hline$A_{5}$ & & -106.4 & & & \\
\hline$\alpha_{12}$ & & & 0.30 & 0.82 & \\
\hline $\mathrm{rms} \Delta H^{E} / \mathrm{J} \cdot \mathrm{mol}^{-1}$ & 0.5 & 0.6 & 2.9 & 1.5 & 1.4 \\
\hline $\operatorname{Max}\left|\Delta H^{E}\right| / \mathrm{J} \cdot \mathrm{mol}^{-1}$ & 1.2 & 1.5 & 5.0 & 3.8 & 3.5 \\
\hline $\operatorname{Max}\left(\left|\Delta H^{E}\right| / H^{E}\right)$ & $3.6 \%$ & $4.5 \%$ & $5.7 \%$ & $11.5 \%$ & $10.5 \%$ \\
\hline DBE (1) + 1-butanol (3) & $\begin{array}{c}\text { Redlich- } \\
\text { Kister }\end{array}$ & $\begin{array}{l}\text { Modified } \\
\text { Margules }\end{array}$ & NRTL & NRTL(3p) & UNIQUAC \\
\hline$\overline{A_{o}}$ & 3414.8 & 1.011 & 2.3362 & 2.4081 & 2160.1 \\
\hline$A_{1}$ & 1259.1 & 1.037 & 0.6854 & 0.8333 & -629.7 \\
\hline$A_{2}$ & 741.4 & -256347 & & & \\
\hline$A_{3}$ & 1310.7 & -0.5147 & & & \\
\hline$A_{4}$ & 1021.8 & 72852 & & & \\
\hline$A_{5}$ & & 201903 & & & \\
\hline$\alpha_{13}$ & & & 0.30 & 0.31 & \\
\hline $\mathrm{rms} \Delta H^{E} / \mathrm{J} \cdot \mathrm{mol}^{-1}$ & 2.9 & 2.4 & 14.3 & 11.9 & 43.2 \\
\hline $\operatorname{Max}\left|\Delta H^{E}\right| / \mathrm{J} \cdot \mathrm{mol}^{-1}$ & 4.9 & 4.0 & 29.0 & 21.8 & 84.5 \\
\hline $\operatorname{Max}\left(\left|\Delta H^{E}\right| / H^{E}\right)$ & $3.5 \%$ & $2.6 \%$ & $8.8 \%$ & $9.7 \%$ & $23.1 \%$ \\
\hline cyclohexane (2)+1-butanol(3) & $\begin{array}{c}\text { Redlich- } \\
\text { Kister }\end{array}$ & $\begin{array}{l}\text { Modified } \\
\text { Margules }\end{array}$ & NRTL & NRTL(3p) & UNIQUAC \\
\hline$\overline{A_{o}}$ & 2339.6 & 0.6024 & 1.9691 & 2.1696 & 1960.8 \\
\hline$A_{1}$ & 1371.5 & 8.2647 & 0.0910 & 0.6426 & -588.4 \\
\hline$A_{2}$ & 1046.8 & 410.0 & & & \\
\hline$A_{3}$ & -1202.8 & 7.181 & & & \\
\hline$A_{4}$ & -2123.2 & 16.9 & & & \\
\hline$A_{5}$ & 3793.8 & 4.5 & & & \\
\hline$A_{6}$ & 4414.9 & & & & \\
\hline
\end{tabular}


1

2

3

4

5

6

7

8

9

10

11

12

13

14

15

16

17

18

19

20

21

22

23

24

25

26

27

28

29

30

31

32

33

34

35

36

37

38

39

40

41

42

43

44

45

46

47

48

49

50

51

52

53

54

55

56

57

58

59

60

\begin{tabular}{|c|c|c|c|c|c|}
\hline$\alpha_{23}$ & & & 0.30 & 0.42 & \\
\hline $\mathrm{rms} \Delta H^{E} / \mathrm{J} \cdot \mathrm{mol}^{-1}$ & 6.5 & 2.6 & 36.3 & 24.8 & 37.2 \\
\hline $\operatorname{Max}\left|\Delta H^{E}\right| / \mathrm{J} \cdot \mathrm{mol}^{-1}$ & 13.6 & 6.0 & 111.2 & 75.7 & 116.0 \\
\hline $\operatorname{Max}\left(\left|\Delta H^{E}\right| / H^{E}\right)$ & $8.0 \%$ & $8.9 \%$ & $33.2 \%$ & $26.2 \%$ & $34.7 \%$ \\
\hline
\end{tabular}

${ }^{a}$ Equivalence between parameters: NRTL $A_{0}=\tau_{12}$ and $A_{1}=\tau_{21}$; UNIQUAC $A_{0}=\Delta u_{12} ; A_{1}=\Delta u_{21}$; Modified Margules $A_{0}=a_{12} ; A_{1}=a_{21} ; A_{2}=b_{12} ; A_{3}=b_{21} ; A_{4}=c_{12} ; A_{5}=c_{21}$ 
Table 5. Experimental excess molar enthalpies $H^{E}{ }_{2+13}$ at $298.15 \mathrm{~K}$ for the addition of cyclohexane to $\left(\operatorname{DBE}(1)+1\right.$-butanol (3)) to form $x_{1} \mathrm{DBE}+x_{2}$ cyclohexane $+\left(1-x_{1}-x_{2}\right)$ 1-butanol, and values of $H^{E}{ }_{123}$ calculated from eq. 5, using the smooth representation of $H_{13}^{E}$ by Redlich-Kister equation with parameters given in Table 4 .

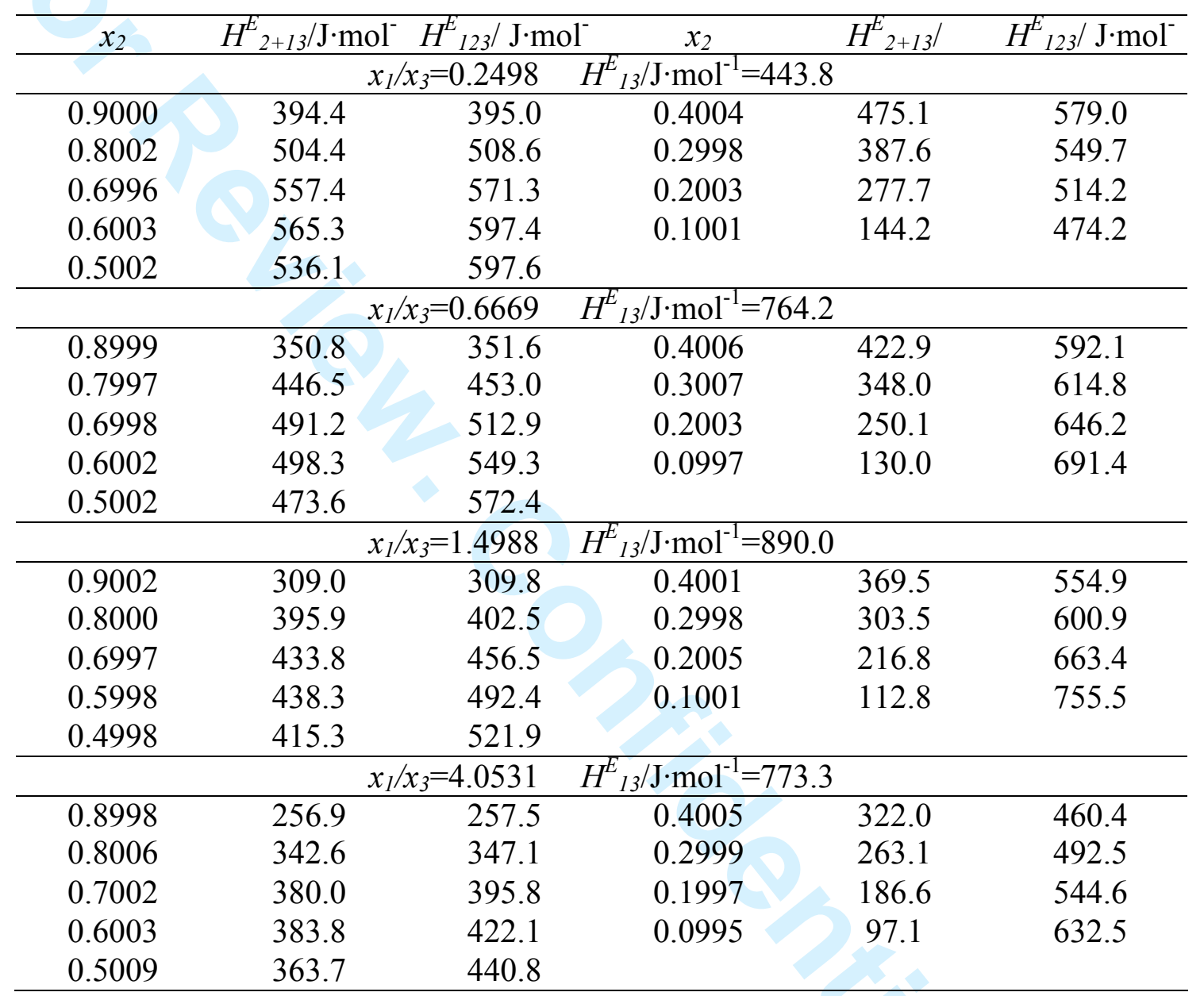


Table 6. Summary of the data reduction and prediction results obtained for the ternary system DBE (1)

+ cyclohexane (2) + 1-butanol (3) at $298.15 \mathrm{~K}$.

\begin{tabular}{|c|c|c|c|c|}
\hline CORRELATION $^{\mathrm{a}}$ & $\begin{array}{l}\Delta H^{E}{ }_{123} \\
\text { (eq. 7) }\end{array}$ & $\begin{array}{l}\Delta H^{E}{ }_{123} \\
\text { (eq. } 8 \text { ) }\end{array}$ & NRTL & UNIQUAC \\
\hline$B_{0}$ & 2586.7 & & -0.3508 & 1294.6 \\
\hline$B_{1}$ & -12380.7 & -1936.1 & 0.4952 & -711.7 \\
\hline$B_{2}$ & -15976.6 & -4187.3 & 1.7410 & 1416.8 \\
\hline$B_{3}$ & 17886.7 & 911.9 & 0.6327 & -389.5 \\
\hline$B_{4}$ & 39625.0 & & 3.7942 & 2869.9 \\
\hline$B_{5}$ & 7477.6 & & 0.1853 & -825.9 \\
\hline$B_{6}$ & -12474.9 & & & \\
\hline$B_{7}$ & -41723.8 & & & \\
\hline$\alpha_{12}$ & & & 0.30 & \\
\hline$\alpha_{13}$ & & & 0.30 & \\
\hline$\alpha_{23}$ & & & 0.30 & \\
\hline $\mathrm{rms} \Delta H^{E} / \mathrm{J} \cdot \mathrm{mol}^{-1}$ & 5.0 & 11.9 & 49.9 & 55.2 \\
\hline $\operatorname{Max}\left|\Delta H^{E}\right| / \mathrm{J} \cdot \mathrm{mol}^{-1}$ & 13.4 & 27.5 & 94.1 & 178.5 \\
\hline $\operatorname{Max}\left(\left|\Delta H^{E}\right| / H^{E}\right)$ & $5.2 \%$ & $8.9 \%$ & $20.0 \%$ & $44.9 \%$ \\
\hline PREDICTION $^{\mathrm{a}}$ & & & NRTL & UNIQUAC \\
\hline$B_{0}$ & & & -0.2065 & -210.2 \\
\hline$B_{1}$ & & & 0.8622 & 467.4 \\
\hline$B_{2}$ & & & 2.3362 & 2160.1 \\
\hline$B_{3}$ & & & 0.6854 & -629.7 \\
\hline$B_{4}$ & & & 1.9691 & 1960.8 \\
\hline$B_{5}$ & & & 0.0910 & -588.4 \\
\hline$\alpha_{12}$ & & & 0.30 & \\
\hline$\alpha_{13}$ & & & 0.30 & \\
\hline$\alpha_{23}$ & & & 0.30 & \\
\hline $\mathrm{rms} \Delta H^{E} / \mathrm{J} \cdot \mathrm{mol}^{-1}$ & & & 207.0 & 169.8 \\
\hline $\operatorname{Max}\left|\Delta H^{E}\right| / \mathrm{J} \cdot \mathrm{mol}^{-1}$ & & & 356.2 & 306.9 \\
\hline $\operatorname{Max}\left(\left|\Delta H^{E}\right| / H^{E}\right)$ & & & $64.2 \%$ & $55.3 \%$ \\
\hline
\end{tabular}




\section{Literature Cited}

(1) Redlich, O.; Kister, A. T. Algebraic Representation of Thermodynamic Properties and the Classification of Solutions. Ind. \& Eng. Chem. 1948, 40, 345-348.

(2) Renon, H.; Prausnitz, J. M. Local Compositions in Thermodynamic Excess Functions for Liquid Mixtures. AIChE Journal 1968, 14, 135-144.

(3) Abrams, D. S.; Prausnitz, J. M. Statistical Thermodynamics of Liquid Mixtures: A New Expression for the Excess Gibbs Energy of Partly or Completely Miscible Systems. AIChE Journal 1975, 21, 116-128.

(4) Alonso, C.; Montero, E. A.; Chamorro, C. R.; Segovia, J. J.; Martín, M. C.; Villamañán, M. A. Excess Enthalpies of Binary and Ternary Mixtures Containing tert-Amyl Methyl Ether (TAME), tert-Amyl Alcohol (TAOH) and Hexane at 298.15 and 313.15 K. Fluid Phase Equilib. 2004, $217,145-155$.

(5) Alonso, C. Ph. D. Thesis, University of Valladolid, Spain, 2001.

(6) Riddick, J. A.; Bunger, W. B.; Sakano, T. K. Organic Solvents, Physical Properties and Methods of Purification; Wiley; New York, 1986.

(7) Rodríguez, A., Canosa, J., Tojo, J. Physical properties of the binary mixtures (diethyl carbonate + hexane, heptane, octane and cyclohexane) from $\mathrm{T}=293.15 \mathrm{~K}$ to $\mathrm{T}=313.15 \mathrm{~K}$. J. Chem. Thermodyn. 2003, 35, 1321-1333.

(8) Iglesias, M., Orge, B., Piñeiro, M. M., Marino, G., Tojo, J. Volumetric properties prediction by cubil EOS for non-ideal mixtures: application to the ternary system acetone + methanol $+\mathrm{n}$ hexane. Thermochim. Acta 1999, 328, 265-275.

(9) Iglesias, M., Piñeiro, M. M., Marino, G., Orge, B., Domínguez, M., Tojo, J. Thermodynamic properties of the mixture benzene + cyclohexane +2 -methyl-2-butanol at the temperature 298.15 
K: excess molar volumes prediction by application of cubic equations state. Fluid Phase Equilib. 1999, $154,123-138$.

(10) Jiménez, E., Segade, L., Franjo, C., Casas, H., Legido, J.L., Paz Andrade, M.I. Viscosity deviations of ternary mixtures di-n-butyl ether +1 -propanol + n-octane at several temperatures. Fluid Phase Equilib. 1998, 149, 339-358.

(11) Rezanova, E. N., Kammerer, K., Lichtenthaler, R.N. Excess enthalpies and volumes of ternary mixtures containing 1-propanol or 1-butanol, an ether (diisopropl ether or dibutyl ether) and heptane. J. Chem. Eng. Data 2000, 45, 124-130.

(12) Marsh, K. N.; Stokes, R. H. Enthalpies of Mixing of n-Hexane + Cyclohexane at 25 ${ }^{\circ}$. J. Chem. Thermodyn. 1969, 1, 223-225.

(13) Murakami, S.; Benson, G. C. Int. Data Series (A) 1974 (1), 19.

(14) Gmehling, J.; Meents, B. Int. Data Series (A) 1992 (3), 144.

(15) Ewing, M. B.; Marsh, K. N.; Stokes, R. H.; Tuxford, C. W. Int. Data Series (A) 1973, 23.

(16) Lundberg, G. W. Int. Data Series (A) 1974 (3), 225.

(17) Savini, G. C.; Winterhalter, D. R.; Kovach, L. H.; Van Ness, H. C. Int. Data Series (A) 1974 (3), 160.

(18) Abbott, M. M; Van Ness, H. C. Vapor -Liquid Equilibrium: Part III. Data Reduction with Precise Expressions for $\mathrm{G}^{\mathrm{E}}$. AIChE Journal 1975, 21, 62-71.

(19) Marongiu, B; Dermini, S.; Lepori, L.; Matteoli, E.; Kehiaian, H.V. Thermodynamics of Binary Mixtures Containing Ethers or Acetals. 1. Excess Enthalpies of Linear Ethers or Acetals + Heptane or + Cyclohexane Mixtures. J. Chem. Eng. Data 1988, 33, 118-122. 
(20) Kammerer, K.; Lichtenthaler, R. N. Excess Properties of Binary Alkanol-Ether Mixtures and the Application of the ERAS Model. Thermochim. Acta 1998, 310, 61-67.

(21) Löwen, B.; Schulz, S. Excess Molar Enthalpies of Cyclohexane + n-Alcohols at 283.15, 298.15, 323.15 and 363.15 K and at a Pressure of 0.4 MPa. Thermochim. Acta 1995, 265, 63-71.

Support for this work came from the Dirección General de Investigación (DGI), Ministerio de Educación y Ciencia, Spain, Projects ENE2006-12620 and ENE2006-13349, and from the Consejería de Educación, Junta de Castilla y León, Spain, Project BU015A06. 